Arab World English Journal (AWEJ) Volume 12. Number3 September 2021

Pp.323-337

DOI: https://dx.doi.org/10.24093/awej/vol12no3.22

\title{
An Empirical Evaluation of Two College English Textbooks in China Based on the China Standards English Framework
}

\author{
Xinying Li \\ Graduate School of the Human Sciences \\ Assumption University, Bangkok, Thailand \\ \& \\ School of Human Sciences, Wenshan University \\ Wenshan City, Yunnan Province, China \\ Corresponding Author: tracy-xinying@qq.com \\ Marilyn Fernandez Deocampo \\ Graduate School of the Human Sciences \\ Assumption University, Bangkok, Thailand
}

Received: 5/16/2021

Accepted: 8/12/2021

Published: 9/24/2021

\begin{abstract}
It is generally known that textbook is the first and the most vital tool for teachers to proceed with successful English language teaching activities. Hence, it is indispensable for all language teachers to evaluate books critically and choose a suitable textbook. This article aimed to explore the different features of two famous college English textbooks utilized in the researcher's school of Wenshan University, Yunnan, China, in alignment with the China Standards English framework, and whether the two books satisfied local students' needs and proficiency. It is hoped to provide an empirical example of textbook evaluation from a Chinese context and inspire local teachers to make possible improvements during evaluating and selecting a textbook. To achieve the objective, a checklist aligned with the framework and a questionnaire was utilized for the collection of comparable data. Moreover, content analysis and percentage were used during the analysis of the two textbooks and students' perception about the textbooks, respectively. Results of the evaluation indicated that the two books are not aligned with the China Standards English framework suggested levels. Both textbook levels tend to be lower than the framework demanded levels, namely level five and six. Students also implied that the textbooks are accessible and seem not to help their language skills improvement. The recommendation is that these textbooks need to be adapted and modified for the English educational practices to suit local students' needs and English proficiency to achieve the China Standards English suggested levels.

Keywords: College English textbook, China Standards English, Chinese context, textbook evaluation, Wenshan University

Cite as: Li, X., \& Deocampo, M. F. (2021). An Empirical Evaluation of Two College English Textbooks in China Based on the China Standards English Framework. Arab World English Journal, 12 (3) 323-337. DOI: https://dx.doi.org/10.24093/awej/vol12no3.22
\end{abstract}




\section{Introduction}

The textbook is always regarded as the most essential resource for language learners and teachers. In the English Language Teaching (after that ELT) classrooms of different levels of Chinese schools, there are $98 \%$ of classroom activities and $90 \%$ of after-class exercises for students are from or adopted from the textbook (Suaréz, 2001, as cited in Liu \& Zhang, 2015). Hence, to evaluate books critically and choose an appropriate textbook becomes essential for all language teachers. They will be able to recognize whether their teaching materials cater to the learners' needs and whether the textbook's content can help students' learning process. However, since the reform and opening up of China in the last century, the number of English textbooks has increasingly grown. In contrast, backwardness of textbook evaluation has become an enormous obstacle for the improvement of English teaching, especially for college English courses. The following part took problems happening in the college English lessons of Wenshan university as an example to show the significance of textbook evaluation in alignment with the China Standards English (after that CSE) framework.

College English is regarded as a required course to be learned by all college students in China. Hence, the choice and evaluation of the college English textbooks become more crucial. Although there are many different kinds of books for the course, it is difficult to choose the most suitable one for all other majored students in various Chinese schools. Most universities choose books from the booklist of China's national plan without deep evaluation, and Wenshan University is one of them. The chosen books in the booklist are from some big Chinese publishers like the Foreign Language Teaching and Research Press and Fudan University Press. Wenshan University is the only state university in Wenshan city and situated in Wenshan City, Wenshan Zhuang, and Hmong Ethnic Autonomous Prefecture, Yunnan Province, China. As an English teacher for more than five years in Wenshan University, China, the researcher found many English teachers do not evaluate books or even do not know how to evaluate a text. Since teachers utilize these texts without in-depth evaluation, they are not clear whether they suit local students' English abilities and needs.

Students in Wenshan University are categorized into three different classes (classes A, B, and $\mathrm{C}$ ) based on their English scores of the Chinese College Entrance Examination (after that CCEE) in the school. Students in classes A and classes B take the i-English Integrated Course essential book as the main coursebook, while students in classes $\mathrm{C}$ take the less complicated textbook the 21st Century College English Students' Book as the main coursebook. The two college English books are made from the mentioned publishers, namely Foreign Language Teaching and Research Press and Fudan University Press. They possess different features. For example, the i-English Integrated elementary version is published by Foreign Language Teaching and Research Press and designed based on the production-oriented Approach (POA) proposed by Wen (2018). It aims to improve students' language productive skills like communicative competence and critical thinking abilities.

During teaching the two books at Wenshan university, the researcher noticed a circumstance. Many students in the school presented low motivation in learning the textbooks because of excess vocabulary and grammar exercises in the two books. In addition, students thought the texts and activities in the books were not very useful for improving their language skills. These problems about students' English proficiency came into question whether the books 
used by the students support their learning needs. Also, since the university used commercial books for teaching and students' learning supplementary materials, were these aligned to their English proficiency level? As these questions were frequently lingering in the researcher's mind, to answer these eternal questions, the development of this research became an actuality.

Furthermore, although the English education in China traced from the last century, few Chinese scholars made in-depth theories on how to evaluate a textbook in local context. For instance, Wang and Zhao (2006) described that there are only a small number of Chinese researchers studying the evaluation methods for college English textbooks, and most of them follow international theories and techniques like Cuningsworth (2002), McDonough, Shaw, and Masuhara (2013) and Tomplinson (2013). The checklists and questionnaires using for textbooks evaluation mainly focus on investigating students' needs and interest surveys while ignoring the relationships with students' English fluency. To develop a localized Chinese method to examine whether the two college English textbooks satisfy Wenshan university students' proficiency levels and needs, it is necessary to take the Chinese local criteria of English abilities into consideration.

Therefore, choosing the CSE framework as a theoretical basis is because the framework is the first Chinese national framework used to describe all levels of English learners' language abilities. The development of the CSE has unified various criteria of English proficiency and testing in different areas of China and is taken as a reference for English language teaching and curricula setting for all educational stages from elementary to higher education. The CSE is recently developed by the Chinese National Education Examinations Authority (NEEA). It is utilized to "define the levels of English ability of Chinese learners and users of English, and describes the features of their English language ability at each CSE level" (Ministry of Education of China, 2018, p.1). It provides Chinese learners and users a scale to measure their English efficiency and achieve their expected levels. This English language ability defined by the CSE is not limited to linguistic competence. Still, it includes the ability to interpret and express the learners' or the users' intended meanings in communication. The CSE aims to identify and unify the learning objectives in the curricula. Currently, CSE research is mostly connected with the introduction of it and English language assessments, like Jin (2017), which was about the construction of CSE in language learning, teaching, and assessment in China. So, this study used the CSE framework for college English textbooks evaluation, which is a first attempt to utilize the CSE in materials evaluation.

Inspired by the researcher's teaching experience at Wenshan University, this study intends to answer the two questions as follows:

1. What are the different features of the two college English textbooks in alignment with the CSE framework?

2. What are students' perceptions of the two college English textbooks based on their learning experience?

Based on the research results, teachers can understand the strengths and weaknesses of the two college English textbooks and make adaptations in their educational practices to cater to students' English proficiency and needs. Moreover, based on the research findings, teachers can 
make recommendations to improve procedures for evaluating, selecting, and developing textbooks aligned with CSE. Additionally, the methods and framework for textbook evaluation and application of CSE can be a good example for Wenshan University and other universities at home and abroad to know Chinese educational documents and textbook policies better. Then, it might enable universities to select appropriate textbooks or materials according to local contexts and situations, or they can adapt contents that need improvement to cater to school missions and students' learning needs.

\section{Literature Review}

\section{Theories of textbook evaluation}

There are various researchers who made different theories on materials evaluation, and the following part revisits the most pervasive works of literature. It includes three aspects, namely the significance of textbook evaluation, basic methods and principles, and circumstances of textbook evaluation in China.

Firstly, textbook evaluation is an essential skill that all teachers and educators should grasp. As McGrath (2002) suggested, textbooks influence what teachers teach, what, and to some extent, how students learn. Richards (2001) also supported the view that textbooks are the critical component and provide the basis for the content of lessons, the essential skills to be grasped, and different kinds of practice students can be involved with. In addition, textbooks guide the development of the syllabus for a course, present examples of language, and offer many valuable resources like the teaching methods and vocabulary for language classrooms (Aftab, 2011). Hence, a suitable textbook can genuinely help teachers a lot for approaching successful teaching activities, while how to evaluate the different textbooks becomes more critical.

Second, there are the following basic methods of textbook evaluation, including an impressionistic overview, in-depth evaluation, checklist, external, internal, and overall evaluation. According to Cunningsworth (2002), the comprehensive impression evaluation refers to the evaluator's subjective assessment of the overall impression of the textbook based on his own experience. For example, the evaluator will skim the publication information and the content design throughout the books and get the various features (Karamoozian, 2008). Additionally, the in-depth evaluation presents the more profound assessment of the teaching materials, which encompasses the topic of language, the method of learning, the organization of content, and the adoption of teaching methods in the textbook. This method also evaluates the adaptability and operability of the book, such as students' needs, the objectives of the syllabus, and the teaching style of teachers. Moreover, Cunningsworth (2002) provides a series of criteria for designing suitable checklists for the selection, which recommends the selected teaching materials should be connected with teaching objectives and satisfy learners' needs. Garinger (2002) also recommends textbook evaluators to assess a book according to adapted or selfprepared checklists, which make sure to include all essential aspects of examine. He also suggested all language educators possess the skills to evaluate teaching materials and to make the best selection to satisfy most students' learning needs and achieve the best learning result. Another significant evaluation method was from McDonough, Shaw and Masuhara (2013) who suggested evaluating textbooks from three aspects, namely external, internal and overall evaluation. The external review considers factors like the degree of difficulty of the language, the utilizing environment, the author's, the cultural orientation, and the vocabulary, audio-visual 
materials, test materials, and so on. While, the internal evaluation requires consideration of the order and difficulty level of the texts, the types and design of exercises, and whether students are interested in the materials. During the process of the overall evaluation process, it demands evaluators to consider the availability, universality, adjustability, and flexibility of the materials.

In terms of evaluation principles, it encompasses two main factors, namely learners' needs, and contexts. On the one hand, McGrath (2002) mentioned that "evaluation (of textbooks) needs to be a learner- and context-related" (as cited in Aftab, 2011, p. 64), textbooks should satisfy learners' ability and needs. Tomlinson (2013) also suggested that it is helpful to develop a set of formal criteria for textbook evaluation and utilize it as a basis to approach subsequent evaluation in the specific context. On the other hand, materials evaluation should consider learners' needs and principles of language learning, which means that the writing of textbooks needs to deal with the target context of use for the materials and the experience of the writers (Tomlinson, 2013). Additionally, Rubdy (2003) proposed that "coursebook criteria are emphatically local" (as cited in Aftab, 2011, p. 64), and the evaluation of textbooks can be proceeded in two stages, namely micro-level and macro-level assessment. For the micro-level, it looks at the users, including 'learners' language and educational backgrounds and interests, teachers' beliefs, the medium, syllabus, and the type of the school. However, the macro-level examines the socio-political environment, like the educational goals, language policy, and roles of the target language prevalent in the country.

Compared with western theories, most Chinese studies on textbook evaluation belong to the review of western ideas and use western approaches to textbook evaluation. Since materials evaluation originates from western countries, many Chinese scholars think it is better to learn from western strategies and theories first. For example, Wang (2021) evaluated the dual cultural schema, namely English and Chinese cultural schema, in the New Horizon College English textbook (the third edition) based on Cunningsworth's teaching material evaluation system. Zhou (2021) utilized McDonough, Shaw, and Masuhara's internal and external evaluation methods to evaluate another college English textbook from an intercultural communicative competence perspective. Additionally, other Chinese teachers and educators just choose the most popular English textbooks from western publishers because they think these books are more authentic because they have been utilized effectively in western countries. So, only a few scholars suggest developing Chinese ways to evaluate English textbooks. He (2002) proposed to evaluate books from five Chinese dimensions. In addition, Zhuang (2005) discussed five principles as well, namely syllabus-oriented, learner-oriented, systematic, alternative, and scientific teaching materials. Wen (2018) also put forward that the writing of textbooks should embody the characteristics of Chinese foreign language teaching. However, these researches mainly rely on scholars' theoretical investigations, while lacks empirical quantitative analysis and practical assessment tools and methods. Therefore, it is essential to establish a set of evaluation frameworks and equipment aligned with Chinese characteristics in ELT classrooms. China must form a set of principles and criteria embodying Chinese features for the writing and development of English textbooks.

\section{Current researches of the CSE framework}

In China, English language education is a compulsory requirement and plays a vital role for all levels of education. However, from Jin et al. (2017), little pieces of research have been 
made about the consistency of English curricula at different levels. There are also no public theoretical models to guide teachers to set curricular requirements and syllabus. With the release of the China Standards English in 2018, it is taken as the national criteria to measure all English learners and users' language proficiency and deal with the inconsistency problem of English language education in China, as well as to enhance the alignment of Chinese learners' English proficiency and tests with the international level. The CSE describes the English language ability of English learners in China from three stages with nine levels and aims to provide guidelines for Chinese learners and teachers in English learning, teaching, and assessment (Liu, 2015, as cited in British Council, 2019). Compared with the three stages with six levels of CEFR, namely Basic (A1-A2), Independent (B1-B2), and Proficient (C1-C2), the CSE divides the English abilities of language learners into three stages, including Elementary (level one-three), Intermediate (level four-six) and Advanced (level seven-nine) stage (see Table one), and provides nearly 3000 'cando' descriptors to depict English learner's overall language ability, listening, reading, speaking, writing, organizational, pragmatic, general interpretation and translation skills. More details of the CSE subscales are on the website of ministry of education of China.

Table 1. The CSE Levels (Ministry of Education of China, 2018)

$\begin{array}{ll}\text { English ability development stages } & \text { Level } \\ \text { Advanced stage } & \text { Level 9 } \\ & \text { Level 8 } \\ & \text { Level 7 } \\ \text { Intermediate stage } & \text { Level 6 } \\ & \text { Level 5 } \\ \text { Elementary stage } & \text { Level 4 } \\ & \text { Level 3 } \\ & \text { Level 2 } \\ & \text { Level 1 }\end{array}$

Currently, most researches of the CSE framework are about the introduction of the framework, the alignment of the framework with other domestic and international tests, and the implementation of the framework (Bai, 2021), while few of them connect the framework with materials development and evaluation. As Alderson (2017) discussed, the CSE is an ambitious project finished only within four years from its start. Hence it still needs many angles of data and revision to develop it further, which means it is necessary to conduct more empirical research to validate the functions and effectiveness of the framework in other areas of English language education. Additionally, Fang and Yang (2017, as cited in Li \& Gu, 2019) suggested verifying the framework with comparative tests and teaching programs to prove the reliability. Liu et al. (2018) upheld implementing of the CSE framework in the development of textbooks and syllabus. He estimates that books would be wrote and developed by the CSE levels so that learners can choose appropriate materials based on their English proficiency levels, and teachers can choose the best materials in educational classrooms as well. Accordingly, Liu (2021) emphasized the significance of the CSE framework for English learning, teaching, and testing. He also suggested improving the framework and connecting it with formative assessment system, summative evaluation, and other assessment systems. Researchers like Luo (2021) and Feng (2021) utilized the framework to guide the listening teaching and develop college students' pragmatic competence.

Recently, Chinese educators and experts are promoting the development of a National English Proficiency Test to unify the varying standards and targets of English language tests in 
the country into a scientific, systematic, and selective one (Wang, 2016). Moreover, to make the CSE connect with international standards, it has been linked with the IELTS and Aptis tests. The results of the linking project are as follows:

Table 2. IELTS and the CSE equivalent results (British Council, 2019)

\begin{tabular}{|c|c|c|c|c|c|}
\hline IELTS & CSE4 & CSE 5 & CSE 6 & CSE 7 & CSE 8 \\
\hline Listening & 5 & 6 & 6.5 & 7.5 & 8.5 \\
\hline Reading & 4.5 & 5.5 & 6 & 7 & 7.5 \\
\hline Speaking & 5 & 5.5 & 6 & 6.5 & 7 \\
\hline Writing & 4 & 5 & 6 & 7 & 7.5 \\
\hline Overall & 4.5 & 5.5 & 6 & 7 & 8 \\
\hline
\end{tabular}

Table 3. Aptis and the CSE equivalent results (British Council, 2019)

\begin{tabular}{llllll}
\hline Aptis & CSE 3 & CSE 4 & CSE 5 & CSE 6 & CSE 7 \\
\hline Listening & 14 & 21 & 29 & 37 & 43 \\
Reading & 16 & 26 & 35 & 42 & 46 \\
Speaking & 21 & 29 & 37 & 43 & 47 \\
Writing & 22 & 31 & 39 & 45 & 50 \\
\hline
\end{tabular}

From the previous literature, a gap was found between textbook evaluation and the CSE framework. There is almost no research that mentions the combination of the two. Hence, the study provides a significant example for both materials evaluation and the implementation of the CSE. The CSE framework in this article not only provides clear and consistent standards for all levels of English learners that might measure their language proficiency, but also is used as a benchmark for teachers to evaluate textbooks and adapt them to the local contexts.

\section{Method}

As mentioned before, this study empirically evaluated two college English textbooks utilized in Wenshan University in alignment with the CSE framework. Hence the two books were the primary data of the research. Additionally, it took students' perceptions of the two books as supporting data for the textbook evaluation. The two books were collected directly in the school, while students' perception data were collected by a questionnaire survey. Accordingly, this study employed mixed-method to collect and analyze both qualitative and quantitative data. The qualitative data was the two textbooks analyzed by content analysis, while the quantitative data was students' perceptions analyzed by percentage statistics. Then, the following parts introduced more details of participants, research instruments, procedures, and study results.

\section{Participants}

Participants of this study are those college students who took part in the questionnaire survey. All college students who have utilized the two textbooks in Wenshan University participated in the survey. Among these students, there were 300 students chosen by the convenience sampling technique as a sample. These students mainly were 18 years old and just finished high school. When they entered Wenshan University, they were required to take the college English course for two semesters, although they majored in different subjects. Depending on their English scores on CCEE test, they were divided and categorized into three classes of A, $\mathrm{B}$, and C. Among the 300 participants, there were 100 male students and 200 female students. Every 100 participants came from the same classes, like classes A, B, and C. 


\section{Research Instruments}

There are two instruments of this study. The one was a checklist based on the CSE framework, and the other was a questionnaire based on students' learning experience of the two books. The following part explains the two instruments more clearly.

Checklist: The checklist examines whether the degree of difficulty and content in the book aligned with the CSE framework. As the CSE framework describes English listening comprehension, reading comprehension, oral expression, and written expression ability in subscales, and each textbook in this study has eight units. So, the checklist combined subscales of the four English language skills in the CSE framework with the exercises and activities of the eight units in each textbook. It divides into four parts of the checklist. The first part has 34 items reviewing the listening texts, and activities of the eight units in the textbooks. The second part has 38 items for examining the reading content of each book. Furthermore, the third and fourth part has 49 items and 54 items respectively. These two parts are for checking the speaking and writing contents of each textbook. The description of all items in the checklist were developed based on the CSE subscales. Moreover, the list had been proved for a pilot evaluation before utilizing it to evaluate the two books. Also, it was verified by three linguistic experts from Assumption University of Bangkok, Thailand.

Questionnaire survey: The survey aimed to collect students' satisfaction about the two college English books based on their learning experience. It was to provide auxiliary data for the evaluation of the two textbooks. Specifically, these questions investigated whether students feel satisfied with the textbooks, whether the textbooks were easy or difficult for them, and whether they were helpful for students to improve their English language skills, including listening, reading, speaking, writing, and translation abilities. This questionnaire consisted of two parts with 17 items. The first part collected students' demographic information, namely gender, age, classes, and used college English textbooks. In addition, the next part included three categories focusing on students' satisfaction about the overall design and contents in books, students' perceptions about the language ability focus in books, and student's perceptions of the difficulty and efficiency of the five language skills contents. Like the checklist, the questionnaire was verified by three linguistic experts from Assumption University. A pilot study also was conducted among 30 students before sending it to all college students. As table four showed, the Cronbach $(\alpha)$ series was 0.715 , which proved the questionnaire was reliable for implementation. After that, the questionnaire was sent to all college English students' QQ groups of each class by a Chinese internet application, namely Wenjuanxing. Almost 300 samples were finally collected.

Table 4. Cronbach series of the questionnaire

Cronbach $(\alpha)$ Reliability Analysis

\begin{tabular}{ll}
\hline Sample & Cronbach $(\alpha)$ series \\
33 & 0.715 \\
\hline
\end{tabular}

\section{Procedures}

The implementation of this study is divided into two steps. The first was the collection of the questionnaire, and the second was the evaluation of textbooks by the checklist and analysis of the questionnaire. Firstly, for the supply to collect students' perceptions, the questionnaire was given out and collected by Wenjuanxing to the QQ groups of students who had utilized the two textbooks during September 2020. The process of collecting data was approved by the consent of 
the dean of the school of foreign languages and every English teacher of each class of Wenshan University. After students finishing the questionnaires online, 300 questionnaires were randomly chosen from types of $\mathrm{A}, \mathrm{B}$, and $\mathrm{C}$ on the Wenjuanxing application as students' perception data of the two textbooks. Secondly, for the analysis of the two data. Contents of the two books were analyzed and aligned with the items of the checklist, while the percentage of students' satisfaction with the two books was calculated.

Specifically, the researcher compared contents of the textbook with items of the checklist, and ticked on the checklist. The content includes requirements of the course outline, text, words, activities and exercises in the textbooks. After that, the researcher summarized all marked items and categorized them. These categorized items were divided into four groups of the four English language skills, namely listening, speaking, reading and writing. Then, the divided items synthesized the features of the textbook. For example, when the researcher evaluated the listening part of i-English College English textbook, she checked the listening exercises of the book firstly, and compared them with items of the checklist. Then she found that these listening activities demand students to listen or watch videos delivered with standard and regular speed, and fill in the blanks with some details extracted from the video. The requirements of these listening activities aligned with subscales of CSE level four which describes the textbook contents should help learners to "understand and note down specific information when listening to radio programs or watching TV programs on general topics when delivered with standard pronunciation and a normal speed" (Ministry of Education of China, 2018, p. 35). Hence it can be concluded that the listening content of the book aligned with the CSE level four.

As for the analysis of questionnaires, the researcher collected 300 questionnaires. These questionnaires were calculated and analyzed by percentage statistics. Moreover, the perception survey data, which outlined the difficulty of textbooks and its efficiency for improving students' language skills, were analyzed using the descriptive analysis. The table 5 presented the percentage of students' perception, which aimed to finalize the result of the analysis by looking at the students' perceptions of the two textbooks.

\section{Results}

Based on the evaluation of the two textbooks, it found three different features. These features are related to the degree of difficulty aligned with the CSE framework, design of exercises and activities, and texts and vocabulary.

A short description of the findings are as follows:

Firstly, the evaluation result using the checklists illustrated that the level of the two textbooks is relatively lower when aligned with the CSE framework. Specifically, the listening and speaking content of the $21^{\text {st }}$-century college English textbook aligned with CSE levels three to four, respectively. The reading content aligned with level three to level four, and the writing content aligned with the CSE level two to level three. According to the CSE framework, the levels three to four of listening ability have illustrated that students understand, obtain essential information, identify other speakers' intentions, make inferences, and identify opinions of different sides and relationships from speeches or talks. It means that they might know how to articulate clearly and deliver the standard pronunciation at a natural speed. Whereas, level three to level four of speaking ability means students can use simple words to 
express views or ideas and give short responses to inquiries from others. These students can participate in group discussions about their daily life, and practicing useful expressions during preparing short speeches as well. While level three to level four of reading skills indicated that students could understand the authors' viewpoints and summarize the main idea of a text. Accordingly, they can find critical information in the text by some reading skills like skimming, scanning etc. Nevertheless, the CSE level two to level three writing skills requires students to write letters for different purposes, namely confirming, verifying, selling, ordering, increasing-price, or resigning.

Additionally, for the i-English college English textbook, the listening was in level three to level four. The speaking and reading content of the text was in level three to level five, and the writing was level four to level five. Compared with the $21^{\text {st }}$ Century textbook, this textbook tends to increase its rank of speaking, reading, and writing content a little to level five. The indication was that learners would describe their experience and personal needs in various ways, find topic sentences and discover more text details for reading abilities. Furthermore, they can also write essential events in one's life, state opinions on familiar topics, and plan the structure of short essays for writing abilities. As Liu et al. (2018) presented, the English proficiency of Chinese college students should achieve the CSE level five to six. Hence the two textbooks seem to be easier for college students, as the evaluation results showed the degree of difficulty of both two books are lower than the CSE levels five to six.

Moreover, the findings of the survey also supported the textbook. Results of the survey indicated that the contents of the textbooks were accessible for students. As shown in table 5, $46.5 \%$ stated the listening materials in the books were easy, $12.74 \%$ expressed that the listening materials were elemental. In comparison, $44.27 \%$ of students think the speaking content is accessible, and $9.55 \%$ of participants feel the speaking materials were elementary. Similarly, the data taken from the students' reflections on reading and writing materials suggested similar results, where $55.73 \%$ and $46.82 \%$, respectively found them easy.

Table 5. The frequency and percentage of students' perception about the degree of difficulty of the two textbooks

\begin{tabular}{|c|c|c|c|c|c|}
\hline \multirow[t]{2}{*}{ Items } & \multirow[t]{2}{*}{ Questions } & \multicolumn{4}{|c|}{ Percentage (\%) } \\
\hline & & Very difficult & Difficult & Easy & Very easy \\
\hline 1 & $\begin{array}{l}\text { Based on your learning experience, what the } \\
\text { degree of the difficulty of the listening contents } \\
\text { of the college English textbooks is? }\end{array}$ & $4.14 \%$ & $36.62 \%$ & $46.5 \%$ & $12.74 \%$ \\
\hline 2 & $\begin{array}{l}\text { Based on your learning experience, what do you } \\
\text { think the degree of the difficulty of the speaking } \\
\text { contents of the college English textbooks is? }\end{array}$ & $3.82 \%$ & $42.36 \%$ & $44.27 \%$ & $9.55 \%$ \\
\hline 3 & $\begin{array}{l}\text { Based on your learning experience, what do you } \\
\text { think the degree of the difficulty of the reading } \\
\text { contents of the college English textbooks is? }\end{array}$ & $1.91 \%$ & $34.08 \%$ & $55.73 \%$ & $8.28 \%$ \\
\hline 4 & $\begin{array}{l}\text { Based on your learning experience, what do you } \\
\text { think the degree of the difficulty of the writing } \\
\text { contents of the college English textbooks is? }\end{array}$ & $2.55 \%$ & $42.36 \%$ & $46.82 \%$ & $8.28 \%$ \\
\hline
\end{tabular}

Concerning the exercises and activities, according to the evaluation using the checklists and questionnaire survey, the two books have emphasized vocabulary and grammar practices rather than language proficiency skills improvement. The result suggested that the unevenness of activities would likely influence students' lack of interest and confidence in English 
learning. For example, in the $21^{\text {st }}$-century college English textbook, out of 22 exercises and activities of each unit, five exercises are listening practice, 12 are reading exercises, two are speaking activities, and the other 3 are translation and writing exercises.

Furthermore, based on 12 exercises and activities of reading, 50\% of the reading part is set to practice students' languages and grammar. These exercises include "filling in blanks", "sentence completion" and "vocabularies and grammar structures". Such activities seemed to practice students' vocabulary and grammar fluency instead of their reading skills. Therefore, it inferred that the distribution of exercises and activities did not apply to help students to improve their language skills.

As for the i-English Integrated coursebook, this has 18 exercises and activities in each unit. Among the 18 exercises, there are four listening exercises, four reading exercises, two translation exercises, one writing exercise, and seven vocabularies and grammar practices. Moreover, from the questionnaire analysis, some students complained that the textbooks focus on activities and grammar points too much. These words and grammatical activities reduced their chances to practice language skills, namely listening, reading, speaking, and writing, hence the lessons became boring.

The third evaluation aspect focuses on the texts and vocabulary. From the result of the questionnaire survey, students reflected that the reading texts in the two textbooks are exciting and not challenging for them to understand, and there are few complicated vocabularies in the texts. So some participated students suggested teachers add more new words in the lessons to increase their language.

It takes several sentences from the two textbooks to be examples as follows:

1. "As both a college professor and parent of a college student, this time of year always seems to raise a variety of thoughts as freshly minted high school graduates to head off to their new adventures." (Wang, 2019, p.5)

2. "Parents and students are nervous, excited, worried about paying bills, and so on."; "Don't be frightened by the faculty." (Wang, 2019, p.5)

These sentences are from the I-English college English textbook. Moreover, from the $21^{\text {st }}$-century college English textbook, the following extracts tend to be accessible.

1. "You're doing well in school, getting involved in several activities outside of school, and preparing yourself for a successful career in the future." (Zhai, 2018, p.4)

2. "Another way to demonstrate respect for your job and your colleagues is to dress appropriately for your job." (Zhai, 2018, p.5)

As the findings suggest that the level of two textbooks did not reach the CSE required level, students who have been using the textbooks might not acquire proficiency level acquired the Ministry of Education in China. 


\section{Discussion}

Textbook evaluation is very crucial for English language learning and teaching, while few Chinese researchers explored appropriate methods for evaluating local books (Wang and Zhao, 2006). For example, Wang (2021) and Zhou (2021) just adopted western methods and checklists into the evaluation of domestic teaching materials. In addition, although other Chinese scholars, namely Wen (2018) and Zhuang (2005), suggested developing Chinese localized strategies for materials evaluation, they did not provide complete theories or empirical experiments. Therefore, this study provided an empirical example of textbook evaluation in the Chinese context, which can be inspirable for all scholars majoring in materials evaluation and development. Moreover, since the construction of the CSE framework, it was regarded as a national benchmark to guide the syllabus, the design of educational activities, and the development of language tests. What current researchers focus on is mainly the introduction and spreading of the framework. For instance, both Bai (2021) and Liu (2021) emphasized the influential role of the framework for domestic ELT classrooms. Liu (2021) also suggested to promote the alignment of the CSE framework with international tests. Hence, comparing with previous researches, the application of the CSE framework in textbook evaluation of this study seemed to be a new area and might stimulate more extensive researches on this domain.

Being grounded in the findings of this research, the degree of difficulty of the book's content was lower than the CSE levels and students' language proficiency. The results reflect two things. The one is that the CSE framework is a good reference for Chinese teachers and publishers in materials evaluation and development. The other is that learners' language ability is a crucial factor for books evaluation. In addition, another finding was the excessive words and grammar exercises in both two books. From the survey results, it presented excess exercises might decrease students' learning interests and confidence. With the exception of the findings, there are some limitations of this study as well. First, the data of the questionnaire survey only from college students of Wenshan university. If the researcher wand to get a very comprehensive reflection of the two books, it might need more students' perception data from other universities in China. On the other hand, the checklist in this study only utilized for evaluating the two college English books, which might need more experiments in other English materials to prove the validity.

\section{Conclusion}

This study intended to present an instance of materials evaluation aligned the CSE framework, which utilized two instruments, namely a checklist aligned with the CSE and assisted with a questionnaire survey based on students learning experience. From the evaluation results, the degree of difficulty of evaluated two books was lower than the CSE levels, and the two books are accessible for local students in Wenshan university.

Generally, the two textbooks choose easy-to-understand texts, motivating students to learn the language and connect relative expressions with actual life. On the other hand, as mentioned, the difficulty levels of the two textbooks are lower than the CSE demanded levels for college students, and most students also consider the textbooks are accessible for them, which would result in the phenomenon that students' English language skills cannot be significantly enhanced in the long term. 
According to the introduction of the two textbooks, both two books can help college students to improve their four language skills. Hence, they should cater to students' language proficiency on average. Whereas, if schools and teachers want to use the two books to help their students reach the demanded language proficiency levels of the national standards, namely the CSE level five to six, they need to adapt the two textbooks to suit local students' proficiency and needs. For instance, teachers can add supplementary materials to increase the difficulty levels of the teaching content and make appropriate tasks to encourage students to practice their language skills. In the meantime, followed researches would proceed with the adaptations of the two books.

\section{About the authors}

Xinying Li is a Ph.D. candidate of Graduate School of Human Sciences at Assumption University, Bangkok, Thailand; She got her MA in Intercultural Communication \& International Management at the Newcastle University of the UK; She is currently an EFL teacher at the School of Human Sciences of Wenshan University, Wenshan City, Yunnan Province, China. Her research interests include Textbook Evaluation and Adaptation, China Standards English, and so on. ORCID: https://orcid.org/0000-0003-0872-6458

Dr. Marilyn Fernandez Deocampo is a full-time lecturer at Assumption University, Graduate School of Human Sciences, Bangkok, Thailand. She currently teaches and supervises MA and doctoral research of ELT programs. Her interests and specialization include Linguistics, English Language Teaching, Language and Society, Language in Media, and Critical Discourse Analysis.

\section{References}

Anderson, J. C. (2017). Forward to the Special Issue "The Common European Framework of Reference for Languages (CEFR) for English Languages Assessment in China" of Language Testing in Asia. Language Testing in Asia, 7(20). DOI: 10.1186/s40468 0170049-9

Aftab, A. (2011). English Language Textbooks Evaluation in Pakistan. Retrieved from https://etheses.bham.ac.uk/id/eprint/3454/1/Aftab12PhD.pdf

Bai, L. (2021). A Summary of "China's Standards of English" Recent Research. Comparative Study of Cultural Innovation, 5(18):145-148.

British Council. (2019). China's Standards of English Language Ability (CSE): Linking UK Exams to the CSE. Retrieved from https://www.britishcouncil.org/sites/default/files/linking_cse_to_uk_exams_5_0.pdf

Garinger, D. (2002). Textbook Selection for the ESL Classroom. Retrieved from: http://www.cal.org/resources/digest/0210garinger.html

Cunningsworth, A. (2002). Choosing Your Coursebook. Shanghai Foreign Language Education Press.

He, A. P. (2002). Foreign Language Syllabus: Teaching materials, Classroom teaching, Design, and evaluation. Guangzhou: Guangdong Education Press.

Hutchinson, T., \& Waters, A. (1987). English for Specific Purpose: A Learning-Centered Approach. Cambridge University Press.

Feng, W. (2021). Exploration of the Development of College English Pragmatic Ability based on China's Standards English. University Education, 101(5), 122-124. 
Arab World English Journal (AWEJ) Volume 12. Number 3. September 2021

An Empirical Evaluation of Two College English Textbooks

Li \& Deocampo

Jin, Y. (2017). Construct and Content in Context-Implications for Language Learning, Teaching and Assessment in China. Language Testing in Asia, 7(12), 1-18. https://doi.org/ 10.1186/s40468-017-0044-1

Jin, Y., Wu, Z., Alderson, C., \& Song, W. (2017). Developing the China Standards of English: Challenges at Macropolitical and Micropolitical Levels. Language Testing in Asia, 7(1), 1-19. https://doi.org/ 10.1186/s40468-017-0032-5

Karamoozian, F. M. (2008). Development of a New Checklist for Evaluating Reading Comprehension Textbooks. ESP World, 7(3), 1-21.

Liu, J. D. (2015). Some Thoughts on Developing China Common Framework for English Language Proficiency. China Examinations, 132(1), 7-15.

Liu, J. D. et al. (2018). < China Standard English Framework> Its Implications for English Teaching, Learning, and Testing. English Language Learning, 283(7), 25-33.

Liu, J. D. (2021). Some Thoughts on Improving China's Standards of English Language Ability in the Context of Educational Assessment Reform. Journal of China Examinations, 201(9), 8- 11.

Li, Y. L. \& Gu, X. D. (2019). A Review of the Research on the Chinese Standards English Proficiency Scale. Foreign Languages and Translation, 26 (1), 85-92. Retrieved from: https://www.ingentaconnect.com/contentone/ince/incecp/2017/00000255/00000005/art00 024

Liu, Y., \& Zhang, J. L. (2015). A corpus-based study of lexical coverage and density in college English textbooks. Foreign Language Education in China, 8(1), 42-50.

Luo, C. (2021). Reform of College English Listening Teaching: Based on an Analysis of China Standards of English. Journal of the Hubei University of Education, 38(6), 91-97.

McDonough, J., Shaw, C., \& Masuhara, H. (2013). Materials and Methods in ELT: A Teacher's Guide (3rd ed). John Wiley \& Sons. Retrieved from: https://www.academia.edu/45173956/Materials_and_Methods_in_ELT_A_TEACHER_S _GUIDE

McGrath, I. (2002). Materials Evaluation and Design for Language Teaching. Edinburgh University Press.

Ministry of Education of the People's Republic of China. (2018). China's Standards of English language ability. Retrieved from http://cse.neea.edu.cn/html1/folder/1505/244-1.htm

Richards, J. C. (2001). The role of textbooks in a language program. Retrieved from: https://www.professorjackrichards.com/wp-content/uploads/role-of-textbooks.pdf https://www.scirp.org/(S(351jmbntvnsjt1aadkposzje))/reference/ReferencesPapers.aspx? ReferenceID $=1542093$

Rubdy, R. (2003). Selection of Materials. In Tomlinson, B. (eds.), Developing Materials for Language Teaching. (pp. 37-57). Bloomsbury Academic Publishing.

Tomlinson, B. (2013). Developing Materials for Language Teaching (2nd ed.). Bloomsbury Academic.

Wen, Q. F. (2018). The production-oriented approach to teaching university students English in China. Language Teaching, 51(4), 526-540. https://doi.org/10.1017/S026144481600001X

Wang, S. L., \& Zhao, Y. (2006). The predicament of the Evaluation of Chinese College English Textbooks and the Way out. China University Teaching, 41(5), 57-60.

Wang, S. R. (Eds.). (2019). i-English An Integrated Course-Basic Book 1. Foreign Language Teaching and Research Press. 
Wang, S. L. (2021). The Evaluation of the Construction of Dual Cultural Shema Based on Cunningsworth's Evaluation System. Journal of Higher Education, 82(22), 82-85.

Wang, A. Z. (2016, Dec 9). China to introduce National English Proficiency Test by 2020. The PIE News. Available at https://thepienews.com/news/china-national-english proficiencytest-2020/

Zhai, X. J., Yu, J. Z., \& Chen, Y. J. (Eds.). (2018). $21^{\text {st }}$ Century College English (S version) Student's Book (2 ${ }^{\text {nd }} E d$.). Fudan University Press.

Zhou, H. (2021). An Evaluation of the College English Textbook Series-New World Interactive English: Reading, Writing \& Translating (Second Edition)- from the Perspective of Intercultural Communicative Competence. [Master thesis, Beijing Foreign Language University]. CNKI. Retrieved from https://kns.cnki.net/KCMS/detail/detail.aspx?dbname=CMFDTEMP\&filename $=1021058$ 460.nh 